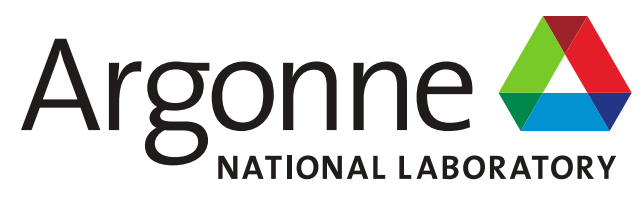

\title{
Preliminary Analysis of a Light Water Ingress Accident for the French High Flux Reactor
}

Nuclear Engineering Division 
About Argonne National Laboratory

Argonne is a U.S. Department of Energy laboratory managed by UChicago Argonne, LLC under contract DE-AC02-06CH11357. The Laboratory's main facility is outside Chicago, at 9700 South Cass Avenue, Argonne, Illinois 60439. For information about Argonne and its pioneering science and technology programs, see www.anl.gov.

\section{DOCUMENT AVAILABILITY}

Online Access: U.S. Department of Energy (DOE) reports produced after 1991 and a growing number of pre-1991 documents are available free via DOE's SciTech Connect (http://www.osti.gov/scitech/)

Reports not in digital format may be purchased by the public from the National Technical Information Service (NTIS):

U.S. Department of Commerce

National Technical Information Service 5301 Shawnee Rd

Alexandria, VA 22312

www.ntis.gov

Phone: (800) 553-NTIS (6847) or (703) 605-6000

Fax: (703) 605-6900

Email: morders@ntis.gov

Reports not in digital format are available to DOE and DOE contractors from the Office of Scientific and Technical Information (OSTI):

U.S. Department of Energy

Office of Scientific and Technical Information

P.O. Box 62

Oak Ridge, TN 37831-0062

www.osti.gov

Phone: (865) 576-8401

Fax: (865) 576-5728

Email: reports@osti.gov

Disclaimer

This report was prepared as an account of work sponsored by an agency of the United States Government. Neither the United States Government nor any agency thereof, nor UChicago Argonne, LLC, nor any of their employees or officers, makes any warranty, express or implied, or assumes any legal liability or responsibility for the accuracy, completeness, or usefulness of any information, apparatus, product, or process disclosed, or represents that its use would not infringe privately owned rights. Reference herein to any specific commercial product, process, or service by trade name, trademark, manufacturer, or otherwise, does not necessarily constitute or imply its endorsement, recommendation, or favoring by the United States Government or any agency thereof. The views and opinions of document authors expressed herein do not necessarily state or reflect those of the United States Government or any agency thereof, Argonne National Laboratory, or UChicago Argonne, LLC. 


\section{Preliminary Analysis of a Light Water Ingress Accident for the French High Flux Reactor}

Prepared by

Jeremy Licht, Aurelien Bergeron

Nuclear Engineering Division, Argonne National Laboratory

September 2017 
(This page left intentionally blank) 


\section{Abstract}

The consequences of a light water ingress accident scenario have been analyzed for the French High Flux Reactor, an heavy-water cooled, moderated and reflected reactor. It is found that the use of safety analysis code such as RELAP or CATHARE are required and neutronic tool alone cannot provide an accurate description of all phenomena involved. It is also found that even a loose coupling between neutronic and safety analysis code can be implemented and used to analyze the accident scenario considered. As a result, despite the substantial reactivity increase induced by the ingress of light water in the core, it is concluded that the RHF reactor would remain safe (peak cladding temperature well below melting temperature) in any conditions considered and at any time. 


\section{Acknowledgements}

This work was sponsored by the U.S. Department of Energy, Office of Material Management and Minimization in the U.S. National Nuclear Security Administration Office of Defense Nuclear Nonproliferation Office under Contract DE-AC02-06CH11357. This work could not have been possible without the close collaboration of the ILL staff and the RHF conversion team. 


\section{Table of Contents}

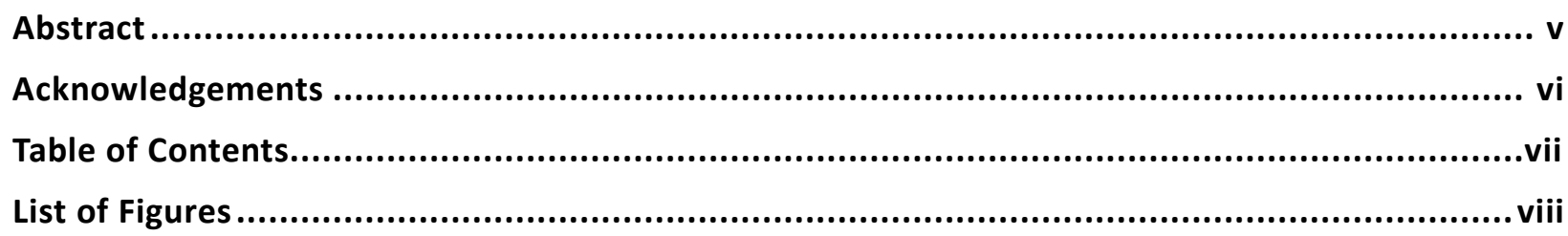

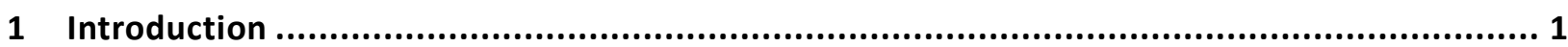

2 The RHF Reactor and Light Water Ingress Accident Scenario ...................................... 2

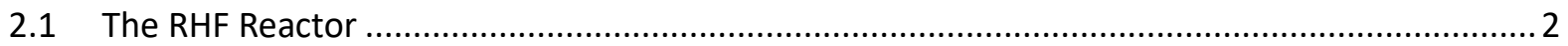

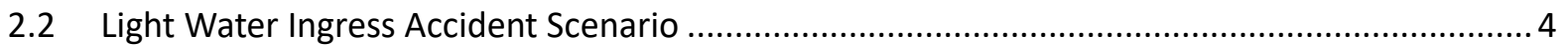

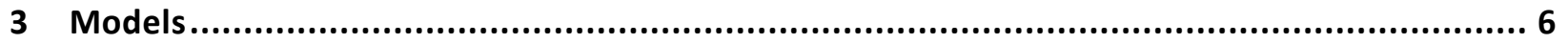

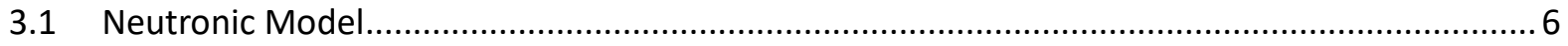

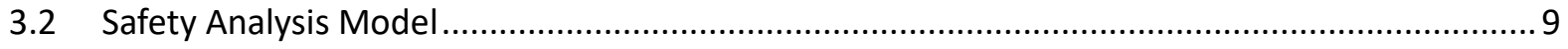

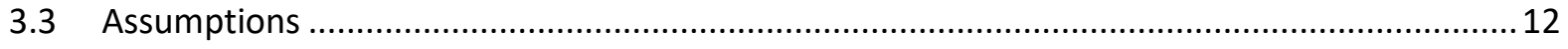

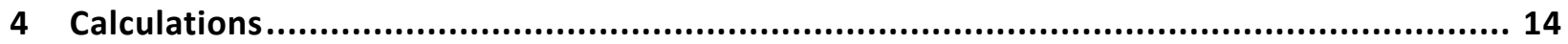

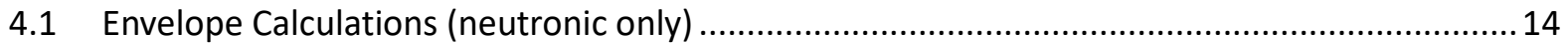

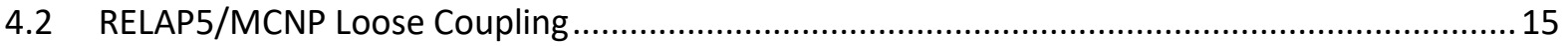

4.3 RELAP5/MCNP Loose Coupling \& Void Feedback Coefficients ................................................ 21

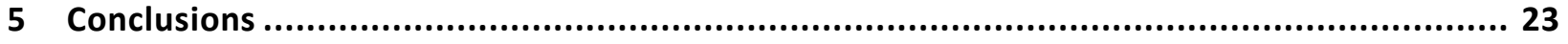

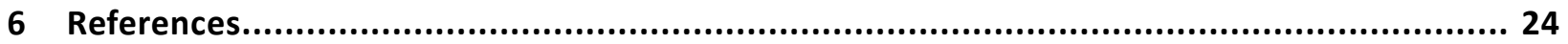




\section{List of Figures}

Figure 2.1-1 - Cross-section of the RHF reactor [Calzavara, 2011].

Figure 2.1-2 - Top view of the RHF reactor; the fuel element is colored in pink. [Calzavara, 2011] .... Error! Bookmark not defined.

Figure 2.1-3 - Dimensions of the RHF HEU fuel plate [Calzavara, 2011] ....... Error! Bookmark not defined.

Figure 2.1-4 - Dimensions of the RHF HEU fuel element [Calzavara, 2011].

Figure 2.2-1 - Schematic of the RHF reactor and location of the break considered in the LWIA analysis. Source: RHF [RHF SAR 2004], figure 23.18 ................................................................................... 5

Figure 3.1-1 - 3D view of the RHF reflector obtained with a simplified neutronics model........................ 7

Figure 3.1-2 - Top view of the fuel element as modeled...................................................................... 8

Figure 3.1-3 - Model details of unit cell (cladding is cyan, fuel is yellow, coolant channel is blue and sideplates are pink).

Figure 3.2-1 - Conceptual drawing of RHF with RELAP5 hydraulic volume numbring (volumes discretization within heavy water tank not shown). 10

Figure 3.2-2 - Left: coolant flow path; right: coolant volume discretization scheme (colored cells) and heat structure linkages (red lines = conduction, red stars = power deposition) in RELAP5 model... 11

Figure 4.1-1 - K-effective evolution caused by the ingress of light water assuming that the accident does not lead to any flow perturbation and ignoring light/heavy water mixing 15

Figure 4.2-1 - RHF HEU RELAP5 model calculated coolant velocity evolution following the light water accident occurring at $\mathrm{t}=0 \mathrm{~s}$. 16

Figure 4.2-2 - light water concentration between the fuel plates (inlet and outlet) for the cases CRA pumps running and stopping...

Figure 4.2-3 - light water concentration in the central cavity (inlet and outlet) for the cases CRA pumps running and stopping...

Figure 4.2-4 - Evolution of the reactivity calculated with MCNP using RELAP5 calculated time-dependent light water concentration.

Figure 4.2-5 - Evolution of the neutron prompt generation time calculated with MCNP using RELAP5 calculated time-dependent light water concentration

Figure 4.2-6 - Evolution of the beta-effective calculated with MCNP using RELAP5 calculated time-

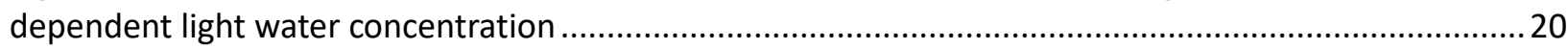

Figure 4.2-7 - Evolution of the peak cladding temperature for the case CRA pumps running ................. 20

Figure 4.2-8 - Evolution of the peak cladding temperature for the case CRA pumps stopping ................2 21

Figure 4.3-1 - void feedback coefficient for the case CRA loop stopping.................................................22

Figure 4.3-2 - Evolution of the peak cladding temperature for the case CRA pumps stopping with and without void feedback coefficient 22 


\section{Introduction}

The French High Flux Reactor (RHF) of the Laue-Langevin Institute (ILL) based in Grenoble, France, is a research reactor designed primarily for neutron scattering experiments supporting applied and fundamental science. It delivers one of the most intense neutron flux worldwide [ILL, 2017]. The reactor currently uses Highly Enriched Uranium (HEU) fuel.

The RHF is cooled and moderated with heavy water. One of the accidents considered in the RHF safety basis [RHF SAR, 2004] is a large light water ingress in the core caused by the complete rupture of the inlet heavy water pipe. In this scenario, the light water would very quickly fill the core region and cause a substantial increase in reactivity. In [RHF SAR, 2004], it is stated that this excess reactivity would be more than compensated by the insertion of the safety rods.

The goal of this study is to analyze this accident with the modern tool suite available (e.g. MCNP, RELAP5). These tools are currently used in conversion to Low Enriched Uranium (LEU) fuel analysis.

The report is organized as follows:

- The second section provides a brief description of the RHF reactor and details the accident scenario considered.

- The third section describes the neutronic and safety analysis models used

- The fourth section describes the calculation results 


\section{The RHF Reactor and Light Water Ingress Accident Scenario}

\subsection{The RHF Reactor}

The RHF reactor has been designed to operate continuously for 45 days per cycle using one element per cycle at a thermal power of $58.3 \mathrm{MW}$ (nuclear power of $57.8 \mathrm{MW}$ ). Originally, 9 elements were burned every two years ( 4.5 element / year). In order to reduce the operation costs, the power has been decreased a few years ago to a thermal power of $53.3 \mathrm{MW}$ (nuclear power of about 52.8 MW) so that the reactor can operate continuously for 49-50 day per cycle and burn 4 elements per year (about 200 days of operation per year).

The reactor is cooled, moderated and reflected by heavy water. It has only one fuel element similar to the Oak Ridge National Laboratory (ORNL) High Flux Isotope Reactor (HFIR) design. The heavy water tank containing the fuel element and the experimental devices has a diameter of $2.50 \mathrm{~m}$ and is about $3 \mathrm{~m}$ tall. It is placed at the bottom of a larger light water pool which has a diameter of $6 \mathrm{~m}$ and a height of $14 \mathrm{~m}$. This pool is placed at the center of a $60 \mathrm{~m}$ diameter cylindrical containment building. The reactor is mainly used for fundamental research, employing 13 horizontal and 3 inclined beam tubes which extract neutrons from the core. One graphite hot source and two deuterium-cooled cold neutron sources are also present in the heavy water tank (later referred to as the reflector). The beam tubes extend through the building's heavy concrete walls. A cross section of the heavy water tank is shown in Figure 2.1-1.

The RHF core has a single annular fuel element made of 280 plates curved as involute, welded to two concentric aluminum tubes. The internal and external diameters of the element are $26.08 \mathrm{~cm}$ and 41.36 $\mathrm{cm}$, respectively. Each fuel plate is bent into an involute shape with an originating radius of $13.681 \mathrm{~cm}$. The advantage of the involute shape is to maintain a constant distance between each plate, simplifying the thermal-hydraulic cooling of such a compact core.

The constant distance between two fuel plates which defines the coolant channel thickness, is $1.8 \mathrm{~mm}$. Each fuel plate has a total height of $90.3 \mathrm{~cm}$. The height of the meat (fissile part of the plates made of dispersed $\left(U A I_{x}\right)$ is $80 \mathrm{~cm}$. On each plate, $3 \mathrm{~cm}$ long borated zones are present at the upper and lower extremities of the fuel. The borated zones act as a reactivity reserve for the End-Of-Cycle (EOC) and to reduce the power peaking occurring on the edges of the plate, especially at the Beginning-Of-Cycle (BOC). The total mass of ${ }^{10} \mathrm{~B}$ in a fresh element is $5.77 \mathrm{~g}$. The overall fuel plate thickness is $1.27 \mathrm{~mm}$. Fuel and borated regions are $0.51 \mathrm{~mm}$ thick. The plate's cladding is made of the aluminum alloy AlFeNi which has a thickness of $0.38 \mathrm{~mm}$ on both sides of the plate The HEU UAlx powder is enriched at $93 \mathrm{wt} \%$ in ${ }^{235} \mathrm{U}$. The powder is dispersed in the aluminum matrix to load $30.6 \mathrm{~g}$ of ${ }^{235} \mathrm{U}$ per plate ( $8568 \mathrm{~g}$ of ${ }^{235} \mathrm{U} / \mathrm{core}$ ). The fuel plate dimensions are shown in Figure 2.1-2.

RHF has a single Control Element (CE) made of two structural aluminum tubes and two absorbing nickel tubes located in the central cavity formed by the annular shape of the fuel element. The RHF control element mechanisms are set up below the fuel element. During the cycle, the control element is 
progressively withdrawn toward the bottom of the vessel. At EOC, the top of the control element is below the bottom of the fuel.

Five Safety Rods (SR) surround the core to shut the reactor down at any time. The safety rods are tubes made of AIC alloy (Ag-In-Cd) filled with heavy water. Each safety rod has a specific angle and position around the core. When fully inserted, their bottoms are located $40 \mathrm{~cm}$ below the reactor median plane. When they are moved along their axes to the fully withdrawn position, their bottoms are located $120 \mathrm{~cm}$ higher, at $80 \mathrm{~cm}$ above the reactor median plane, with the same angle.

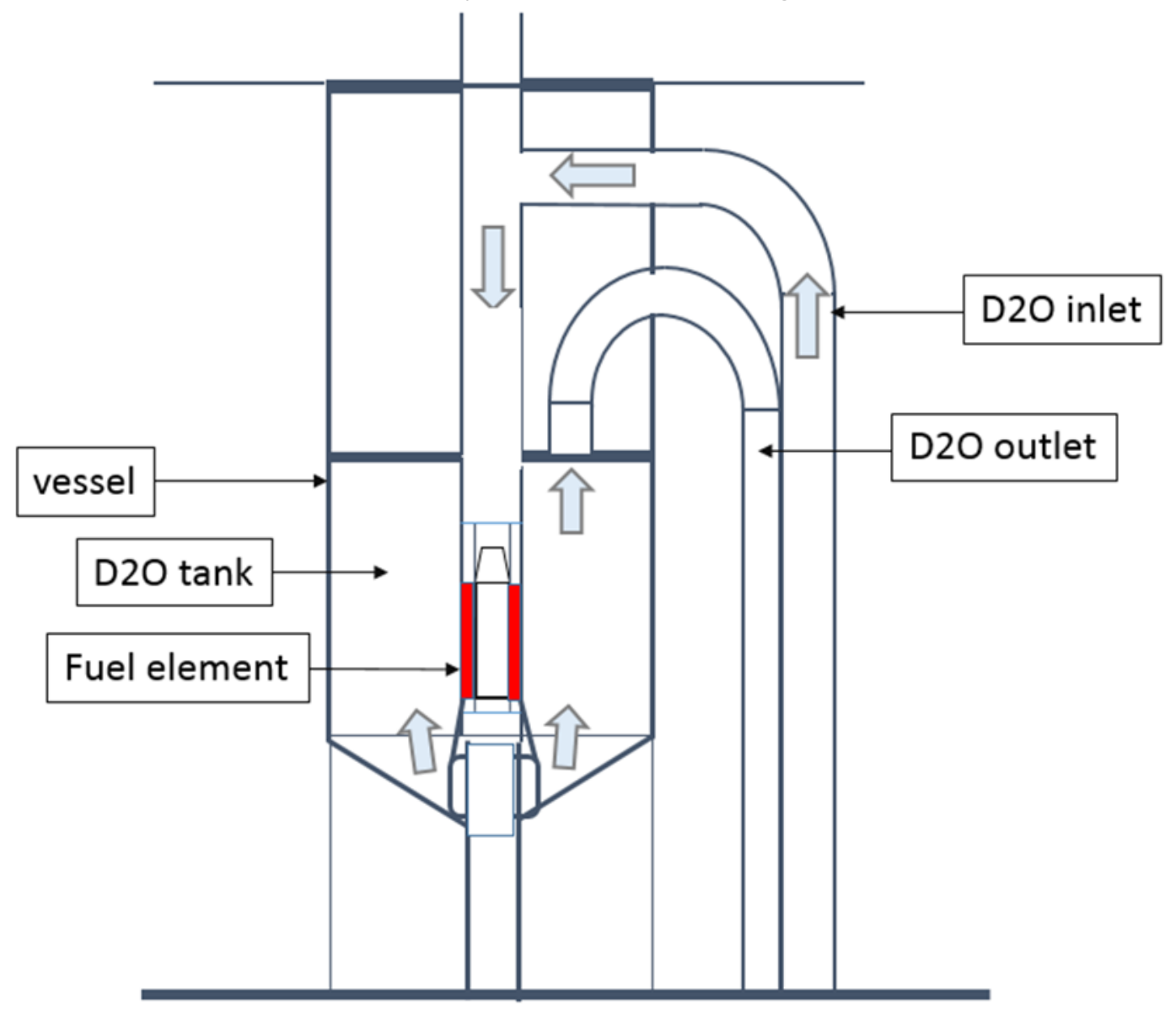

Figure 2.1-1 - Cross-section of the RHF reactor 


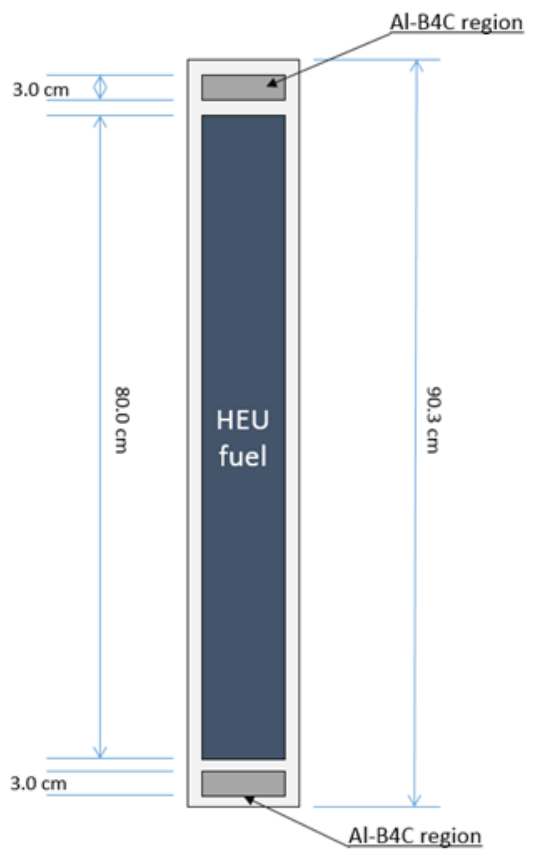

Figure 2.1-2 - Dimensions of the RHF HEU fuel element

\subsection{Light Water Ingress Accident Scenario}

One of the accident scenarios considered in the RHF safety basis [RHF SAR, 2004] is a large light water ingress in the core caused by the complete rupture of the inlet heavy water pipe. The detailed of the accident are explained below.

\section{Accident Scenario:}

1) Considering the reactor operating at nominal conditions (nominal power, nominal flow, control rod at critical position) and at beginning of cycle (most reactive state), is considered a complete rupture of the inlet heavy water just before the chimney (see Figure 2.2-1 below, the rupture is about $4 \mathrm{~m}$ away from the top of the element). The failed pipe being surrounded by light water, a significant ingress of light water occurs, replacing progressively the heavy water within the core.

2) The pressure in the light water pool is 2.15 bar and about 15 bar in the chimney. The pipe rupture would therefore induce a significant variation in pressure in the chimney which will be detected by the plant control system. In the RHF SAR, it is estimated that it would take 400 ms for the plant to detect the pressure drop and initiate the release of the safety rods. It is unclear if the main and CRA loops are ordered to stops at that moment. In the presented analysis, it is assumed that the main pumps are tripped at $400 \mathrm{~ms}$ (not an immediate stop due to their high inertia). Regarding the CRA loop, two cases are considered:

- $\quad$ CRA pumps tripped at $400 \mathrm{~ms}$

- $\quad$ CRA pumps continue running indefinitely 
3) Four (out of five) safety rods are fully inserted $660 \mathrm{~ms}$ after the accident, the most efficient safety rods is considered stuck in its upper position during the entire sequence. Even assuming the worst, the light water would not have reached the core inlet at that time. Therefore, thanks to the four inserted safety rods, the reactivity would first drop significantly.

4) Considering the characteristic of the plant and the difference of coolant velocity between the plates and the central cavity in particular, it is expected that the light water will reach the bottom of the fuel before any significant quantity can be present in the central cavity leading to the most unfavorable reactivity state and a very rapid increase of reactivity.

5) Then, the light water would progressively enter and fill the central cavity leading to a second reactivity drop and a stable situation where the reactivity remains strongly negative.

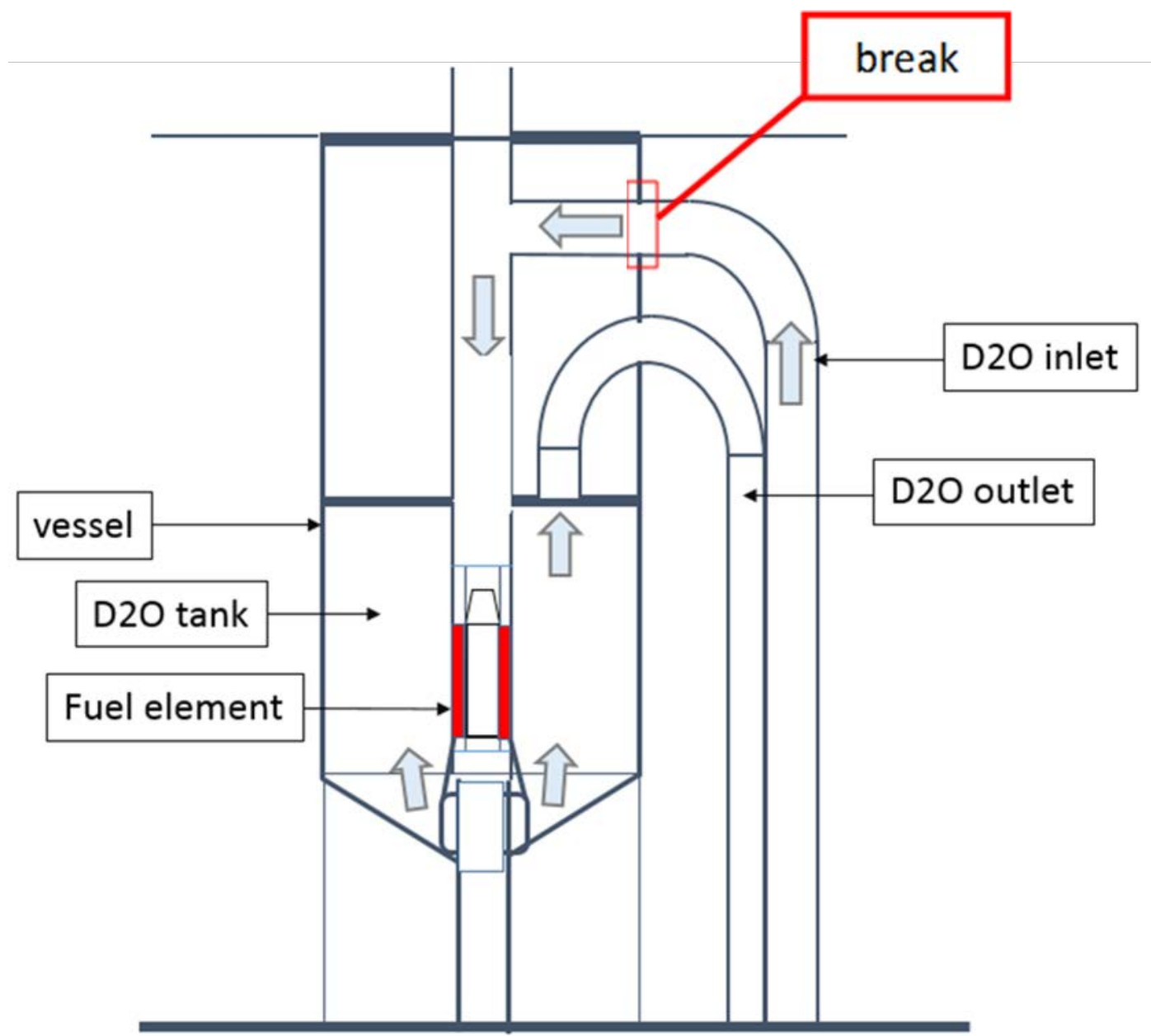

Figure 2.2-1 - Schematic of the RHF reactor and location of the break considered in the LWIA analysis. 


\section{Models}

In this section, the numerical models used are described.

\subsection{Neutronic Model}

The Monte Carlo N Particles (MCNP) computer code has been selected to perform the neutronic calculations. This software package is developed by Los Alamos National Laboratory (LANL) [LANL, 2008a], [LANL, 2008b]. It is used primarily for the simulation of nuclear processes and particle interactions such as neutrons, photons and electrons. Its range of application is very large and covers, among other things, medical physics, fission and fusion reactor design, criticality and radiation protection. The MCNP code has a large base of users worldwide and has often been benchmarked against experiments. Its ability to model complex geometries in three-dimensions (3D) and calculate a wide variety of parameters (eigenvalues, neutron flux, spectrum...) make the code an excellent tool for the study of complex systems such as RHF.

ILL neutronics model of the RHF is very detailed, modeling accurately all in-core components up to the concrete walls that extend beyond the reactor vessel. ILL developed such model to cover their own analysis needs (e.g. dose calculations, etc...). All neutronics analysis and modifications made by the conversion team are based on this original ILL model. More details on the different aspects of the model can be found in [Calzavara, 2011] and [Bergeron, 2010].

As stated before, modifications have been applied to the model since the release of the feasibility report [Bergeron, 2010] and some other since the release of the OECD-NEA benchmark [Calzavara, 2011].

Since the release of the feasibility report, the following modifications to the model were made:

- Corrections in the fuel dimensions and compositions (one compensating the other, no change in reactivity was observed).

- More detailed description of the anti-turbulence grids at the exit of the element (relatively large difference of reactivity was obtained at EOC simulation which happens to improve the comparison to experimental data).

- Re-definition of the heavy water cells in the reflector (considerable improvement in memory use which accelerates calculation efficiency).

- Replacing old cold source design by new one (no change in reactivity was observed).

- Corrections to the definitions of beam tubes $\mathrm{H} 3, \mathrm{H} 4, \mathrm{H} 8$ (no change in reactivity was observed).

- Applying density and temperature (energy) information to the material definitions to reflect full power conditions (improved comparison to depletion experimental data).

- Complete redefinition of the fuel plates which were modeled as piece of arc instead of involute following the method described in [Calzavara, 2011] (no change in reactivity was observed but considerable acceleration of calculation time and possibility to apply exact same meshing as in 3D T-H analysis). 
Additional modifications to the model were also made after the OECD-NEA benchmark report [Calzavara, 2011] was released:

- Corrections in orientation of very cold neutron extraction tubes inside the cold source (no change in reactivity was observed).

- Corrections of the involute orientation (no change in reactivity was observed).

- Generation of a set of cross section at specific temperature (corresponding at full power condition) for all material isotopes used in the model.

All the modifications mentioned above did not affect the good agreement between the HEU model and the experimental data. 3D views of the reflector obtained with a somewhat simplified version of this model are shown in Figure 3.1-1. Screenshots of a top view of the fuel element and detailed of one plate are shown in Figure 3.1-2 and Figure 3.1-3. These figures have been obtained with the MCNP code Visual Editor [Vised, 2014].
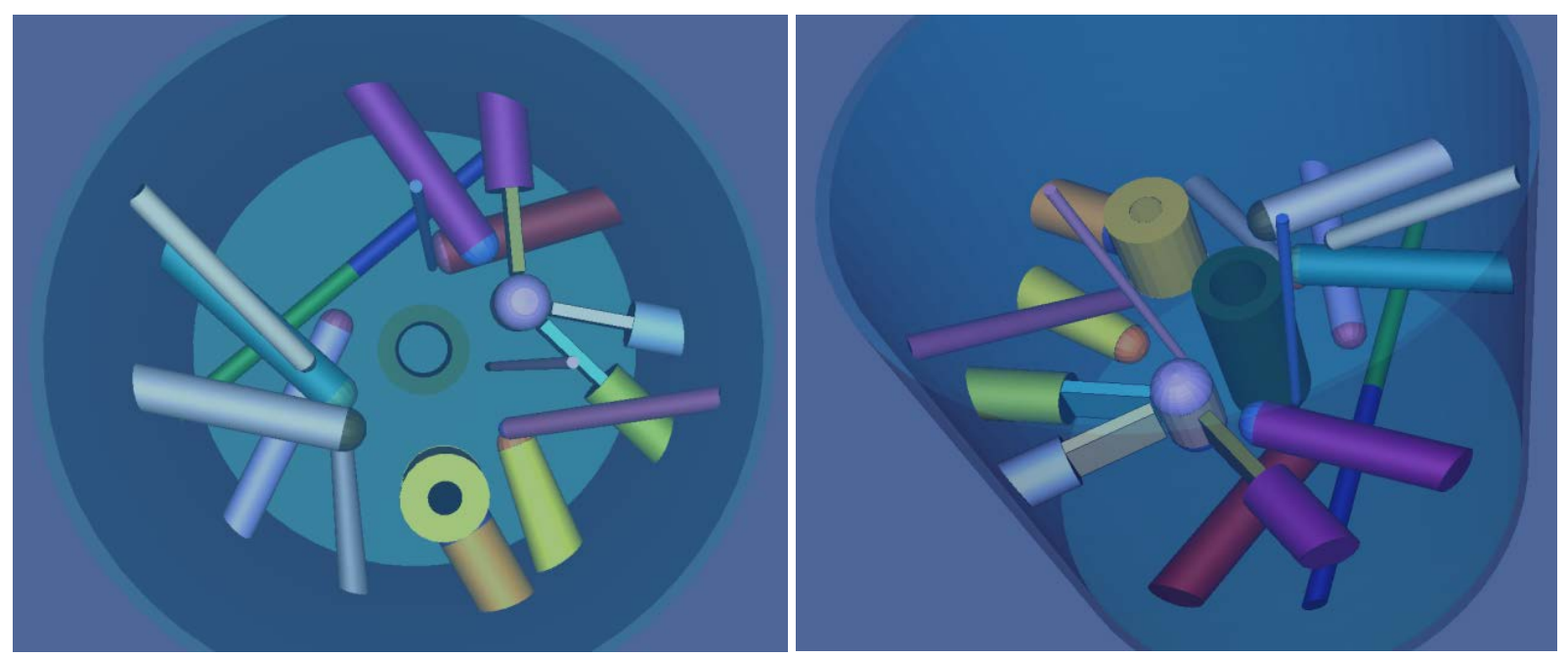

Figure 3.1-1 - 3D view of the RHF reflector obtained with a simplified neutronics model 


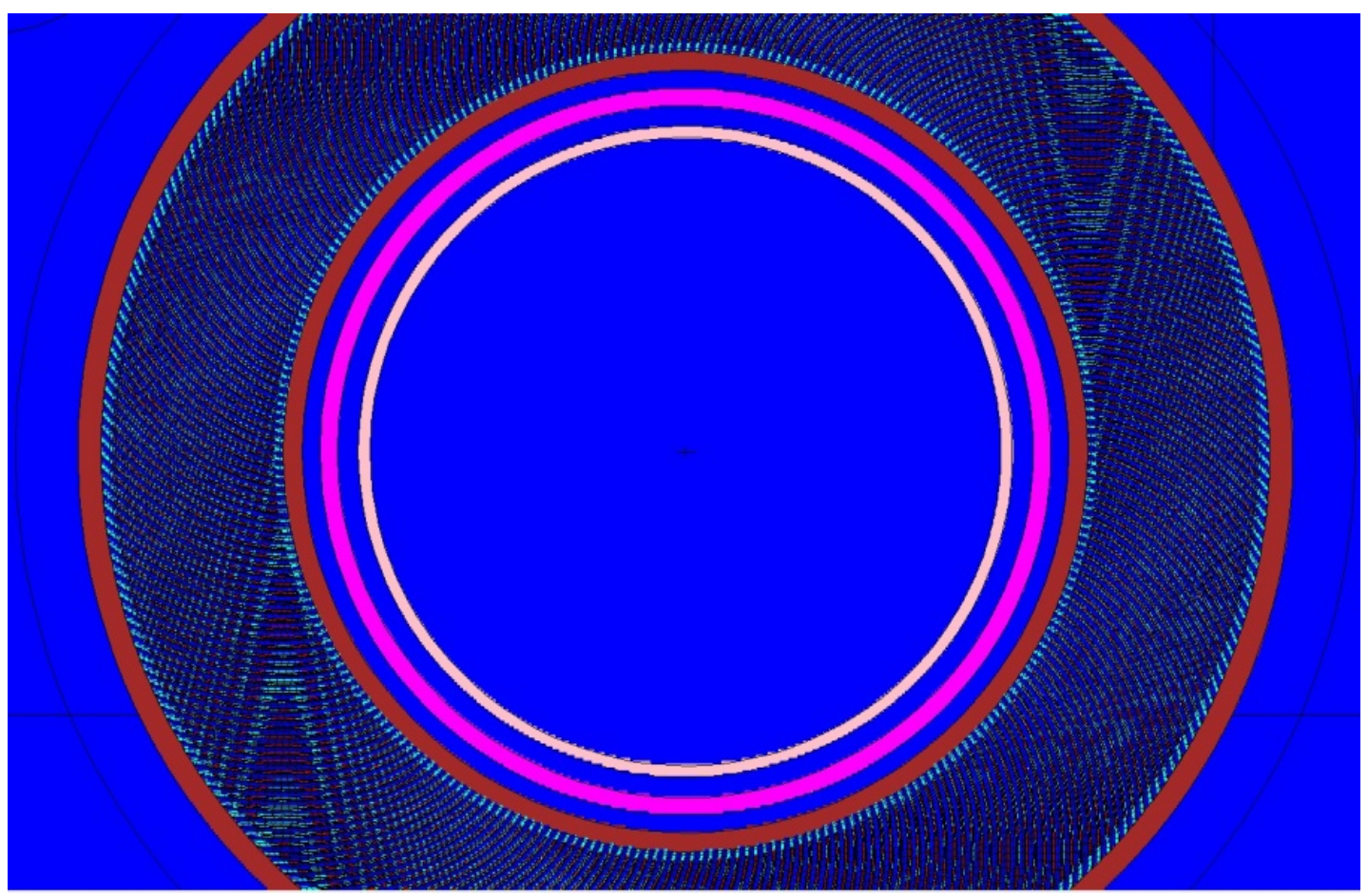

Figure 3.1-2 - Top view of the fuel element as modeled

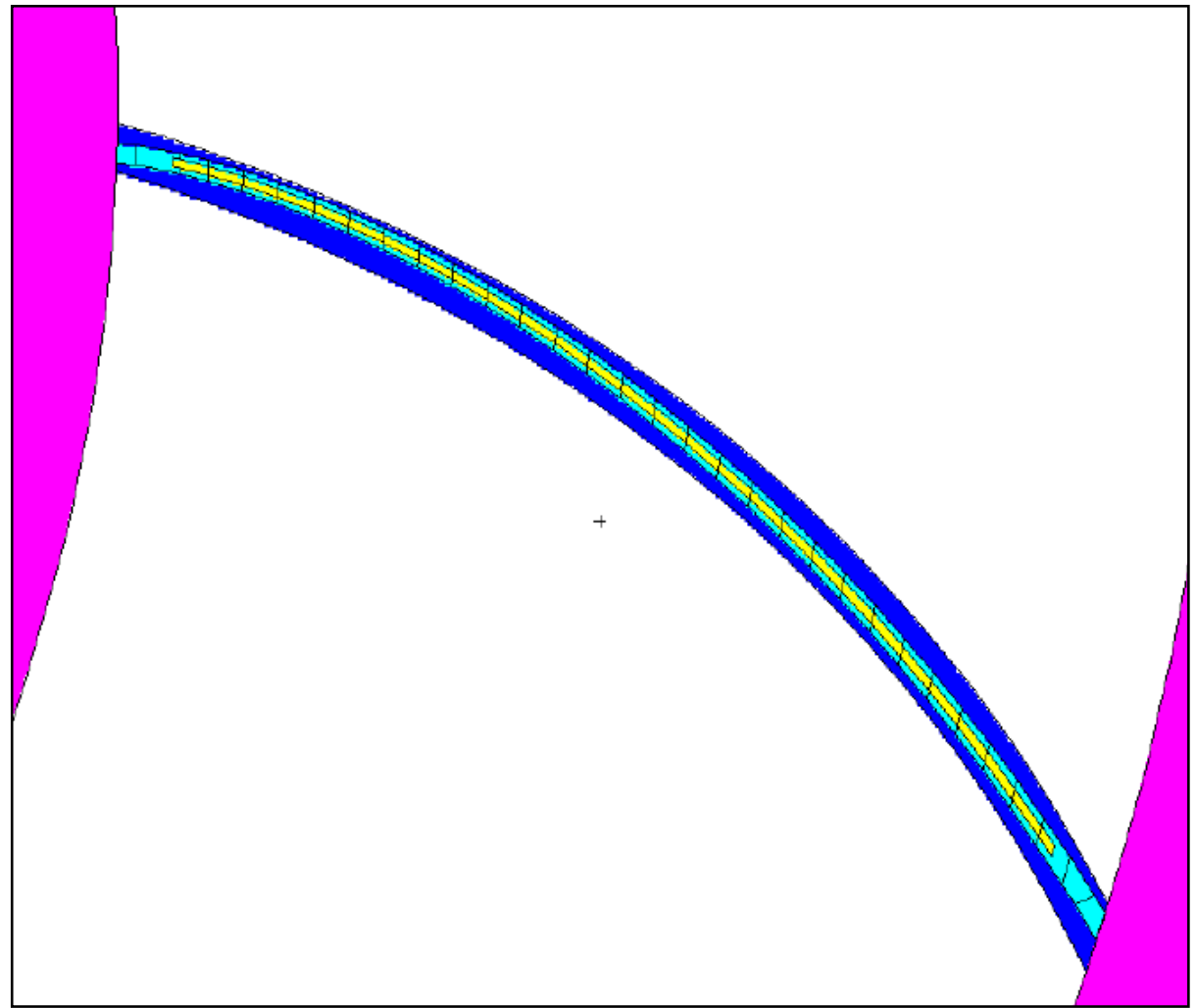

Figure 3.1-3 - Model details of unit cell (cladding is cyan, fuel is yellow, coolant channel is blue and sideplates are pink) 


\subsection{Safety Analysis Model}

The RELAP5/MOD3.3 reactor transient analysis code was used for this work. The code was developed with a generic modeling approach to allow best-estimate simulation of postulated accident scenarios for a wide range of thermal hydraulic systems [ISL, 2003]. Although the code has been primarly used for analysis of light water power reactors, it has been successfully used to perform safety analyses for the conversion of research reactors from highly enriched uranium (HEU) to low enriched uranium (LEU) fuel [Dionne, 2014].

A RELAP5 model of RHF was previously developed at ANL to support conversion from HEU to LEU fuel [Licht, 2015]. Figure 3.2-1 shows a color-coded conceptual drawing of the RHF reactor as modeled in RELAP5. The reactor vessel, located at the bottom of a light water pool (volume 5), consists of a chimney (Volumes 14 to 24) and heavy water tank. Heavy water coolant flows downward through the chimney and splits to separately cool the annular fuel element and centrally located control rod.

The control rod coolant flows into the CRA loop while the fuel element coolant flows through the reflector tank and into the primary loop. As indicated in Figure 3.2-1, a portion of the CRA loop has not been included in the RELAP5 model; instead it has been approximated with inlet and outlet mass flow boundary conditions (490 through 493).

The primary loop is defined by volumes 120 through 256 . Reactor flow in the primary loop is controlled by the speed of the primary pumps (168 and 169). The coolant inlet temperature is controlled through the temperature and heat transfer coefficient boundary condition applied to the secondary side of the primary heat exchangers (194).

The pressure control system consists of an expansion vase (364-366), cover gas (380) and pressurization pumps. The pressurization pumps are not included in the RELAP5 model. For steady-state simulations, the pressurization is controlled with a time dependent pressure boundary (370) and the relatively small flow rate generated by the pressurization pumps was neglected. For transient simulations, the pressure can be controlled by the time dependent volume (370) or by the cover gas (380), depending on which valve (371 or 365 ) in the model is open.

To prevent accidental draining of the core in an accident scenario, the RHF reactor includes anti-syphon lines for the primary (276 to 288 ) and CRA loop (472 to 488). The anti-syphon line for the CRA loop operates continuously, in contrast to the anti-syphon line for the primary loop which contains a passively controlled valve that remains closed during normal operation.

Natural circulation lines (500 to 504 and 510 to 514) are available to promote cooling of the fuel element and control rod during an accident, but also contain passively controlled valves that remain closed during normal operation. 
A hot and cold break in primary piping where included for LOCA simulations (800's). The cold leg break was located at volume 223 and the hot leg break was located at volume 159.

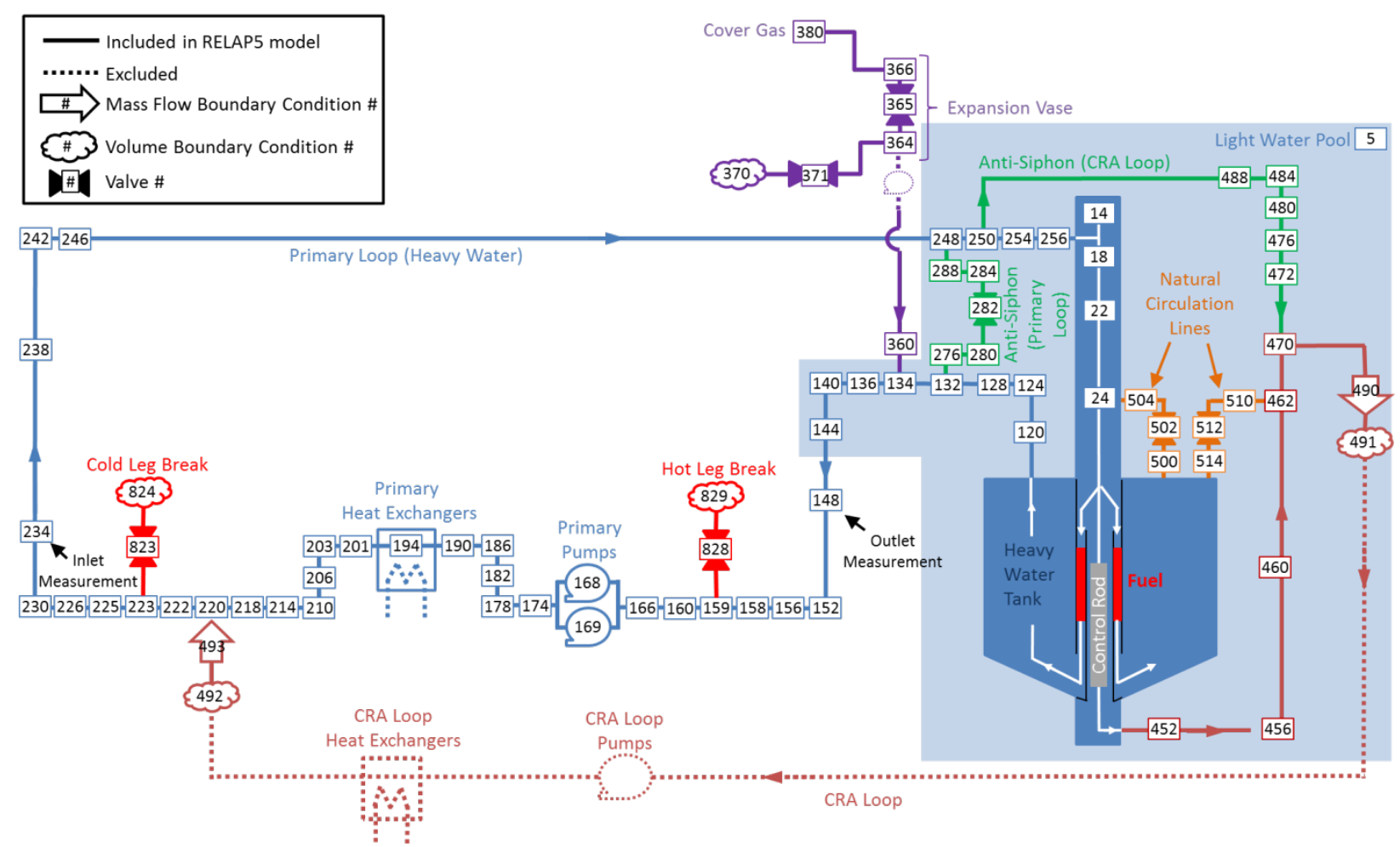

Figure 3.2-1 - Conceptual drawing of RHF with RELAP5 hydraulic volume numbring (volumes discretization within heavy water tank not shown) 

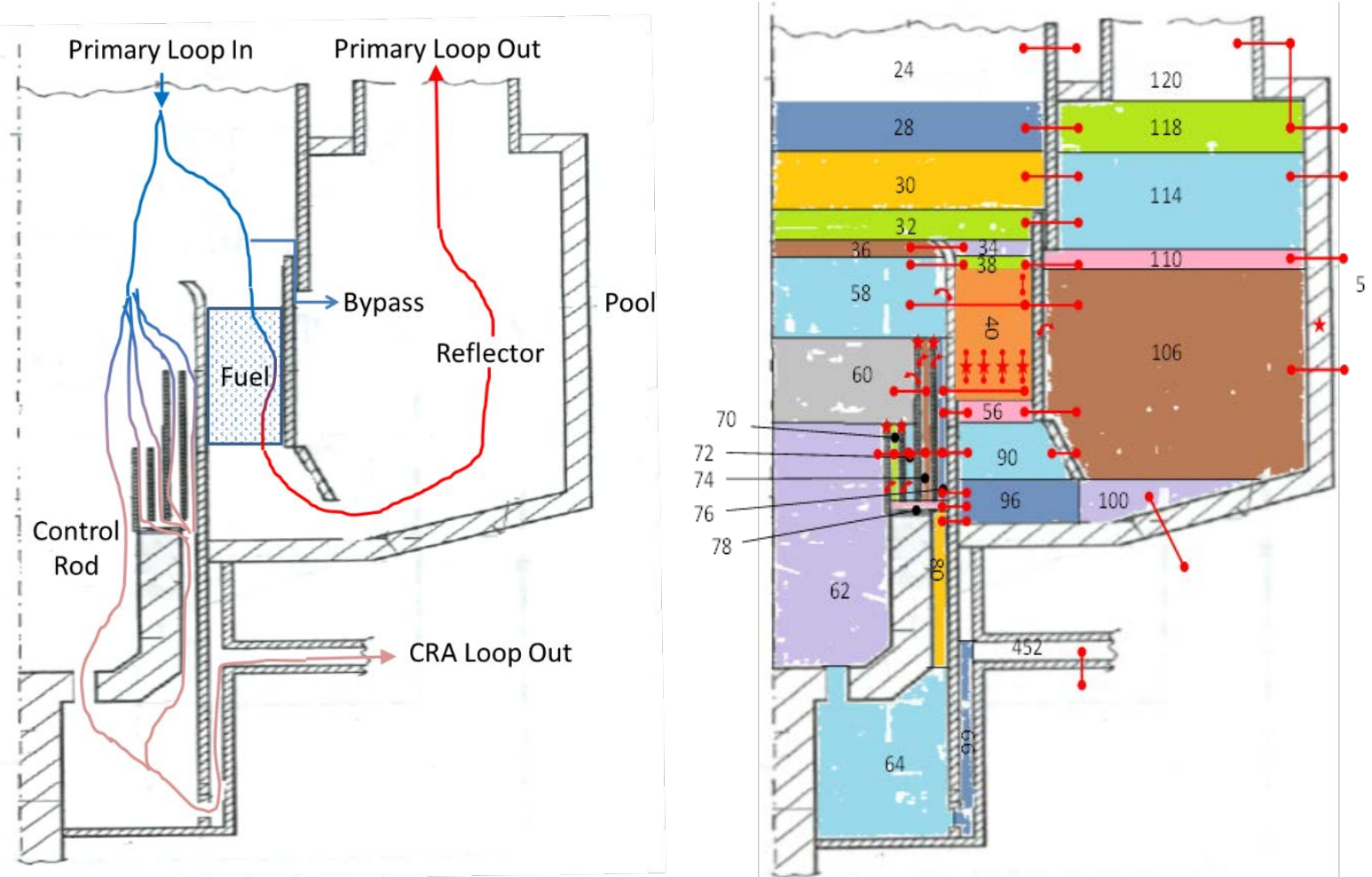

Figure 3.2-2 - Left: coolant flow path; right: coolant volume discretization scheme (colored cells) and heat structure linkages (red lines = conduction, red stars = power deposition) in RELAP5 model.

The RELAP5 model of RHF was used to perform verification of system transients previously modeled with the CATHARE code. Verification simulations were performed for the following scenarios:

steady-state reactor operation,

$>$ total loss of electrical power accident,

$>$ total loss of electrical power with locked primary pump impellers accident, and

$>$ Hot and cold leg loss of coolant accident (LOCA):

0 A break in the hot leg of $114 \mathrm{~mm}$ in diameter located $3.7 \mathrm{~m}$ upstream of the primary pumps.

0 A break in the cold leg of $140 \mathrm{~mm}$ in diameter located downstream of the pumps (16.8 meters before the core inlet).

Excellent code to code agreement was found for pressure, temperature, and flow rate distribution at steady state conditions.

There was, in general, good agreement between codes for the transient simulations and the observed peak cladding temperatures. There are, however, some differences in the RELAP5 model which are expected to provide better results. For example, the RELAP5 models more accurately the minor loss coefficients for tee junctions. This impacts the natural circulation flow in the RELAP5 model. While direct measurements of the natural circulation flow are not available, the impact is indirectly seen in the improved comparison of the pump coast down data. A second difference in the RELAP5 model is the modeling of helium in the accumulator. The CATHARE model used steam as a surrogate since helium was not supported by the code. Compartive studies performed with the RELAP5 model suggest that there are 
significant differences in the system transient depending on which (steam or helium) is used in the accumulator. This was especially true for Hot leg LOCA's.

\subsection{Assumptions}

The RELAP5 model described above has been used as the basis for preliminary large light water ingression analysis. Nominal conditions in the model are given in Table below:

Table 3.3-1 - Nominal conditions assumed in RELAP5 model.

\begin{tabular}{|l|c|c|}
\hline & RELAP5 Value & $\begin{array}{c}\text { RELAP5 Model Location } \\
\text { Volume (node) }\end{array}$ \\
\hline Primary Loop Mass Flow Rate & $734.2 \mathrm{~kg} / \mathrm{s}\left(2407 \mathrm{~m}^{3} / \mathrm{hr}\right)$ & 174 \\
\hline CRA Loop Mass Flow Rate & $24.9 \mathrm{~kg} / \mathrm{s}\left(81.5 \mathrm{~m}^{3} / \mathrm{hr}\right)$ & 490 \\
\hline Inlet Temperature & $26.6^{\circ} \mathrm{C}$ & $234(1)$ \\
\hline Pressure at A13 & 4.0 bara & $148(3)$ \\
\hline
\end{tabular}

The simulation transients are based on 1987 data for primary and CRA pump coast down. For a coast down transient, the CRA loop flow rate goes to zero in approximately 8 seconds. The primary loop flow rate goes to zero in approximately 250 seconds. The natural circulation valves open at about 25 seconds.

Only three changes to the model have been implemented for this work:

1) An inlet pipe break was added to the RELAP5 model between volumes 254 and 256 (see Figure 2.2-1 and Figure 3.2-1). A large break LOCA has been modeled by instantly closing a valve to isolate the upstream from the downstream piping while simultaneously opening valves to connect them to the light water pool. The RELAP5 code cannot model a mixture of light and heavy water. The light water in the pool is therefore modeled with heavy water containing traces of boron. Following the accident, the amount of boron present in each volume of the RELAP5 model is recorded and compared to the concentration set in the pool. In a given volume, it is assumed that the ratio of the two boron concentrations is equivalent to the ratio of light/heavy water.

2) The control rod position for verification studies was located at the core midplane. For light water ingress analysis, the control rod was repositioned to the critical position $(+23 \mathrm{~cm}$ from the core midplane).

3) The volume nodes in the fuel element are consistant with the axial discretization used in the MCNP model while the control rod volumes use a simplified node discretization. To simplify data exchange between the two codes, the control rod node discretization was made similar to the fuel element region. This change has no noticeable impact on the RELAP5 simulation results.

There are several items identified during this work that need consideration in future efforts:

1) The current nominal operating conditions should be modeled. Consideration should also be given to simulation of off normal operation, such as at the limiting safety system settings. 
2) Use of a recent primary pump coast down curve with and without CRA pump trip, as well as the CRA pump coast down curve, to capture any changes to the RHF hydraulic system that have been implemented since the 1987 data (e.g. pump, heat exchanges, etc...)

3) Consideration to explicitly model CRA loop. The CRA loop has not been implemented in the RELAP5 model since the data was not readily available and not considered necessary for the verification of historical system transients. This assumption needs to be reviewed for simulating the light water ingress accident. 


\section{Calculations}

The following describes the calculation performed to date. They go in order of sophistication.

\subsection{Envelope Calculations (neutronic only)}

In a first step, we study the evolution of reactivity following the accident assuming that it does not lead to any flow perturbation. This case is unrealistic (the flow will be perturbed immediately after the accident due to the significant pressure difference occurring in the chimney) and simplistic (assume no light/heavy water mixing) but useful because these simplifications lead to the worst possible reactivity state (assuming full flow conditions, the fuel plates would be surrounded by $100 \%$ light water well before any substantial light water could reach the central cavity).

The calculated k-effective evolution is shown in Figure 4.1-1. As one can see:

- The k-effective remains very stable the first $400 \mathrm{~ms}$ after the accident (safety rods are not inserted yet and light water entered the tank but is still too far away from the fuel element to lead to a reactivity change.

- From $t=400$ to $t=660 \mathrm{~ms}$, the k-effective drops significantly, from 1.0 to $\sim 0.74$ which corresponds to the phase where the four less efficient safety rods are inserted.

- The k-effective remains stable at 0.74 for a short period of time ( $140 \mathrm{~ms})$ until the light water starts entering the core ( $800 \mathrm{~ms}$ after the accident) which leads to a significant reactivity increase. The core is critical again at $\mathrm{t}=840 \mathrm{~ms}$ and reach its maximum value at 1.0203 at $\mathrm{t}=845 \mathrm{~ms}$. This is the most reactive state one can imagine and it cannot be higher than that.

- The k-effective then remain relatively constant until $t=1300 \mathrm{~ms}$ until the light water finally fills the central cavity leading to a second reactivity drop. Ignoring what happens in the reflector (which is also progressively being filled with light water, reducing further the reactivity), once the central cavity is entirely filled by light water ( $t=2400 \mathrm{~ms})$, the $k$ effective has dropped to a value of 0.86 .

The above findings appear to be in contradiction with what is stated in [RHF SAR 2004] in which it is explained that the additional reactivity supplied by the light water is more than compensated by the negative reactivity of the safety rods. It is unclear why the presented analysis and the SAR differ so much. Since the k-effective is found to be well above 1.0 and for a substantial amount of time, the SAR accident description, based on reactivity only, appears insufficient to guarantee the safe behavior of the reactor. A more sophisticated approach, based on a more realistic modeling of the flow in the main and CRA loop is required. 


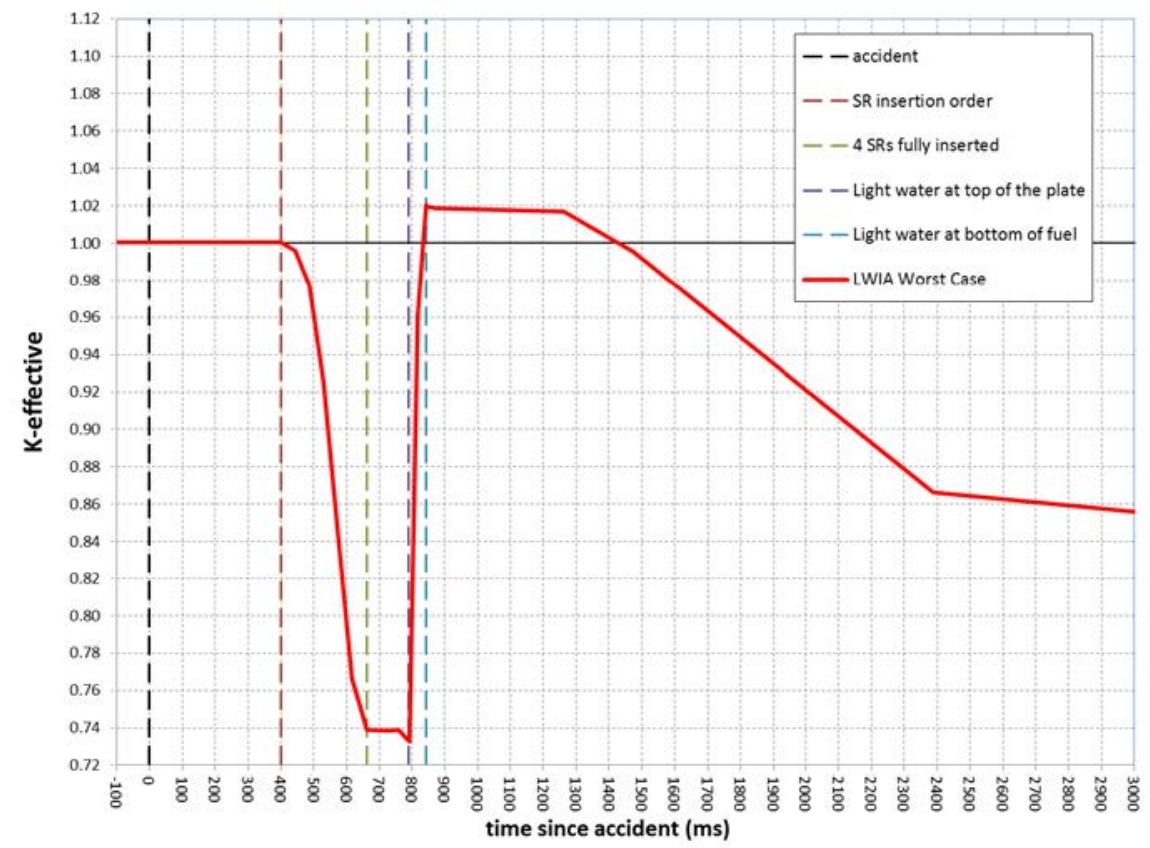

Figure 4.1-1 - K-effective evolution caused by the ingress of light water assuming that the accident does not lead to any flow perturbation and ignoring light/heavy water mixing

\subsection{RELAP5/MCNP Loose Coupling}

The light water ingress accident has been modeled with RELAP using the ANL model developed in 2014 (which has given satisfying results when compared to historical transient analyses using the CATHARE code and experimental pump coastdown data [Licht, 2015]). The breach has been modeled by instantly closing a valve to isolate the upstream from the downstream piping while simultaneously opening valves to connect them to the light water pool. However RELAP5 cannot model a mixture of light and heavy water. The light water in the pool is therefore modeled with heavy water containing traces of boron. Following the accident, the amount of boron present in each volume of the RELAP5 model is recorded and compared to the concentration set in the pool. In a given volume, it is assumed that the ratio of the two boron concentrations is equivalent to the ratio of light/heavy water.

\section{First step: RELAP5 run to extract time-dependent light water concentration}

In a first step, kinetic parameters and reactivity evolution are not modeled for effects due to light water. The light water concentration evolution in each volume of interest is calculated and then modeled in the neutronic model to calculate the light-water-concentration-dependent evolution of the reactivity. Since the behavior of the main and CRA loops are unknown, two cases have been considered:

- Main and CRA pumps tripped at $\mathrm{t}=400 \mathrm{~ms}$ after the accident

- Main pumps tripped at $\mathrm{t}=400 \mathrm{~ms}$ after the accident but CRA pumps continue running

As can be seen in Figure 4.2-1 for both cases, the coolant velocity decreases significantly and immediately after the accident. This is caused by the significant pressure differential occurring in the chimney. However, the coolant velocity within the fuel plates remains significantly higher than in the central cavity. Figure 
4.2-2 and Figure 4.2-3 show the evolution of the light water concentration within the fuel plates and within the central cavity, respectively.

On Figure 4.2-2, one can see that there is very little difference between the cases of CRA pumps running (dashed lines) or stopping (solid lines). In both cases, it takes about 2 seconds for having $90 \%$ light water between the fuel plates. Also, even if the coolant velocity between the plates goes from 17 to about $6 \mathrm{~m} / \mathrm{s}$, it takes only about $130 \mathrm{~ms}$ for the light water to go from the inlet (blue curves) to the outlet of the fuel plates (red curves).

Meanwhile, one can see on Figure 4.2-3, representing the light water concentration in the central cavity, that significant differences exist between the cases CRA pumps running (dashed curves) and stopping (solid curves). In the case of CRA pumps running, it takes about 2.75 seconds to reach a concentration of light water equal to $90 \%$ at the inlet of the central cavity (blue dashed curve). This value jumps to 6 seconds in the case of CRA pumps stopping (blue solid curve). Because the coolant velocity in the central cavity is approximately an order of magnitude lower than the velocity between the fuel plates, it also takes a substantial amount of time to fill up the central cavity with light water. In the case of CRA pumps running, the outlet of the central cavity (red dashed curve) is $90 \%$ light water 9.25 second after the accident. In the case of CRA pumps stopping, the outlet of the central cavity (red solid curve) is barely $30 \%$ light water 13 second after the accident (the RELAP5 runs stops arbitrarily at 13 seconds but could be easily expanded).

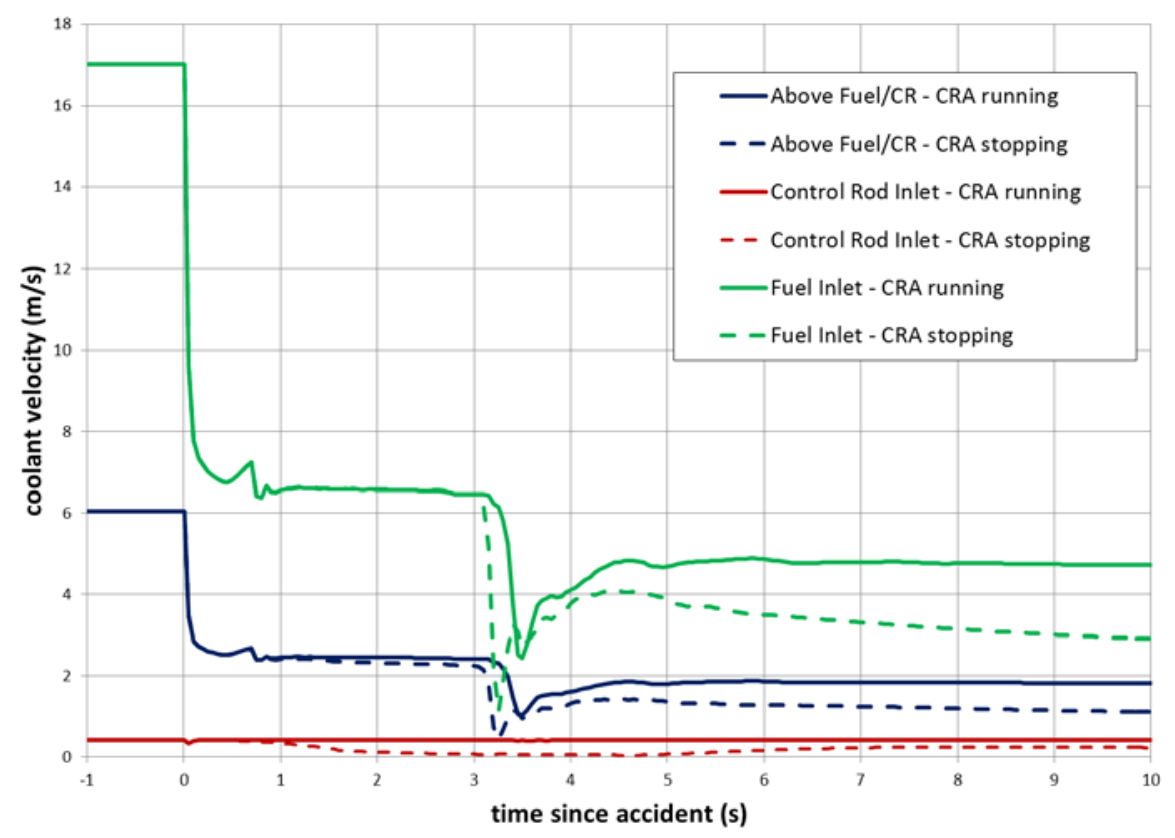

Figure 4.2-1 - RHF HEU RELAP5 model calculated coolant velocity evolution following the light water accident occurring at $\mathrm{t}=0 \mathrm{~s}$ 


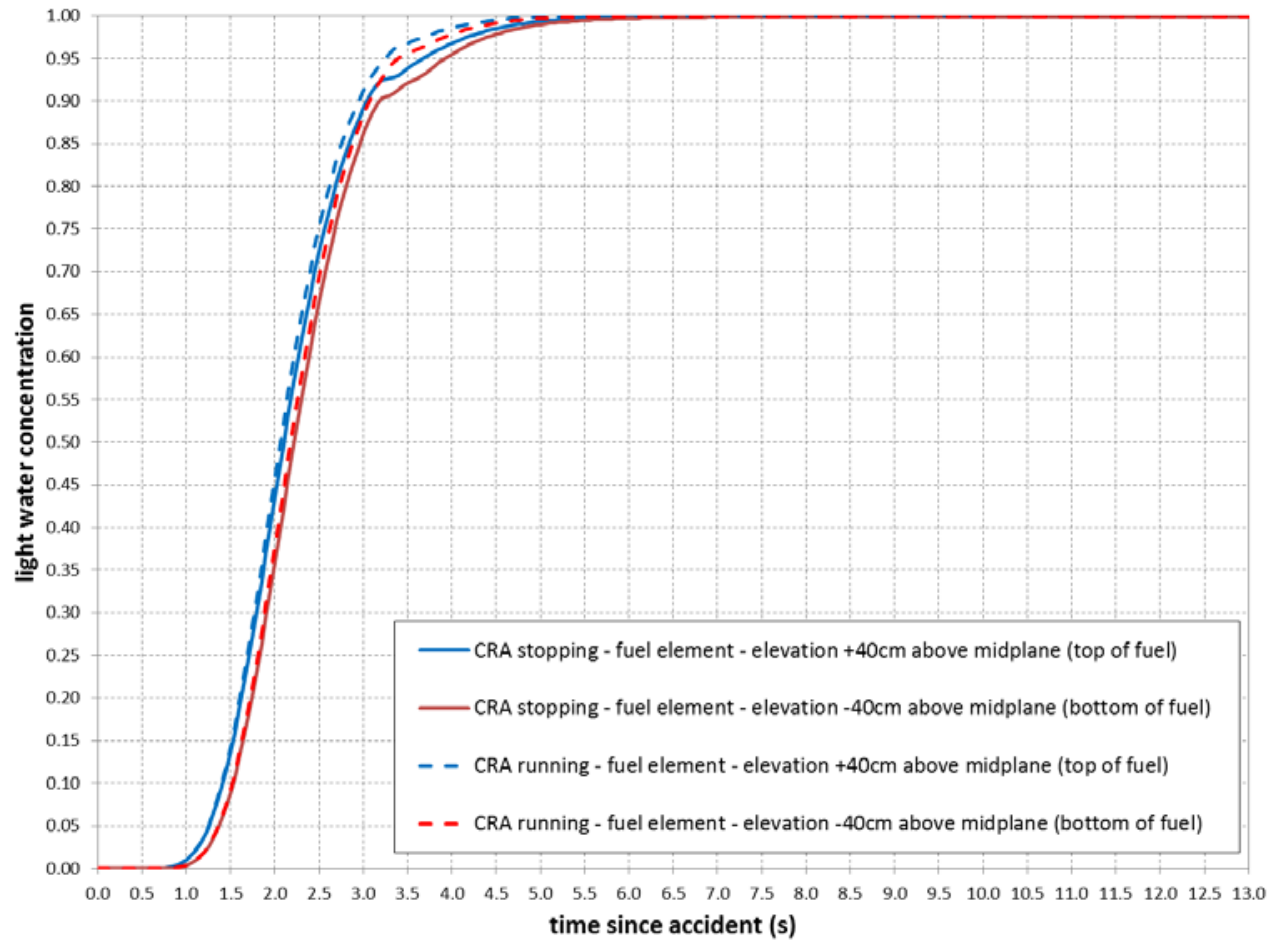

Figure 4.2-2 - light water concentration between the fuel plates (inlet and outlet) for the cases CRA pumps running and stopping

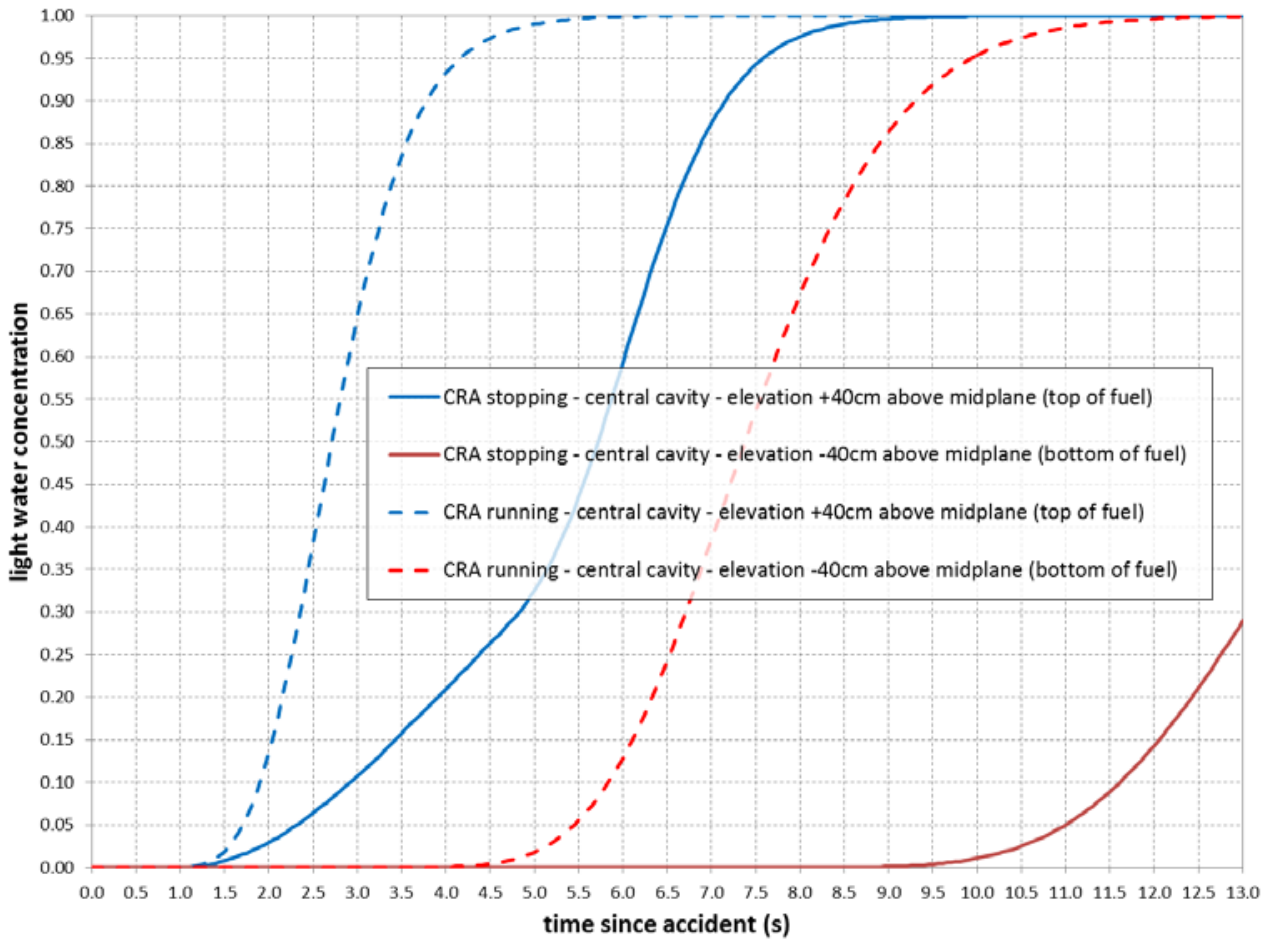

Figure 4.2-3 - light water concentration in the central cavity (inlet and outlet) for the cases CRA pumps running and stopping 
Second step: MCNP run using RELAP5 time-dependent light water concentration to extract reactivity, kinetic parameters evolution

In a second step, the time-dependent light water concentrations, obtained from the RELAP5 run described above, have been implemented into the RHF MCNP model. The entire sequence has been modeled (13 seconds) using half a second time increment for a total of 26 time steps. The RELAP5 coolant volume discretization has been implemented into the MCNP model. The reactivity evolution for the two cases of CRA pumps running and stopping is illustrated on Figure 4.2-4.

It can be seen on this figure that the shape of the reactivity curves is similar to the one obtained in Figure 4.1-1 (no flow perturbation case): the reactivity first decreases sharply due to the safety rods insertion; then increases rapidly when the light water reaches the fuel plates; finally the reactivity decreases again when the light water fills the central cavity.

If the shape of the curves for the two cases treated is quite similar, there is however significant differences in magnitude. In particular, it appears clearly that the reactivity for the case of CRA pumps stopping becomes positive for a substantial amount of time (about 2.5 seconds) while for the case of CRA pumps running, the reactivity remains negative during the entire sequence. This is due to the difference of light water concentration evolution in the central cavity.

The neutron prompt generation time and beta-effective have also been calculated. They are presented on Figure 4.2-5 and Figure 4.2-6, respectively. There are very little differences between the cases of CRA pumps running and stopping. In both cases it can be seen that the beta-effective is worth about $700 \mathrm{pcm}$ at the beginning of the sequence and increases linearly and very slightly up to a worth about $750 \mathrm{pcm}$ at the end of the sequence. The neutron prompt generation time however decreases sharply when the light water starts to fill the space between the plates. It is worth $650 \mu \mathrm{s}$ at the beginning and drops to about $200 \mu$ s once the light water is between the plates $(t=3 s)$. It remains relatively stable afterwards.

\section{Third step: $2^{\text {nd }}$ RELAP5 run using MCNP time-dependent reactivity and kinetic parameters}

In a third step, the reactivity evolution as well as the kinetic parameters evolution obtained with MCNP is modeled in RELAP5. Reactivity feedback coefficients are however not modeled yet. With these inputs, the power evolution can be calculated as well as the coolant, cladding and fuel temperatures. The evolution of the peak cladding temperature for the case of CRA pumps running and stopping is shown in Figure 4.2-7 and Figure 4.2-8, respectively. Due to RELAP5 limitations, the kinetics parameters had to be set as constant values during the entire sequence. To see if the kinetic parameters play an important role, each case has been ran twice, using the $t=0$ and $t=13$ s kinetic parameters values. It can be seen on Figure 4.2-7 and Figure 4.2-8 that, despite the substantial differences in kinetic parameter value (in particular the prompt generation time), there is virtually no differences in cladding temperature.

For the case of CRA loop running, it can be seen on Figure 4.2-7 that the peak clad temperature reaches a maximum value of about $150^{\circ} \mathrm{C}$ at $\mathrm{t}=1 \mathrm{~s}$ and decreases afterwards to reach a very stable value of less than $50^{\circ} \mathrm{C}$. This finding seems to show that if the CRA loop keeps running, the reactor would remain safe.

For the case of CRA loop stopping, it can be seen on Figure 4.2-8 that the evolution of the peak clad temperature is very similar to the previous case up to $t=2.5 \mathrm{~s}$. Afterwards, due to the fact that the reactivity become positive and for a substantial amount of time, significant coolant vaporization starts to occur between the fuel plates, leading to a very rapid and significant increase of the clad temperature which is found to far exceed the melting temperature of aluminum (about $550^{\circ} \mathrm{C}$ ). This finding seems to show that if the CRA loop stops, the reactor would experience a severe fuel element meltdown. However, recall that the reactivity feedback coefficients have not been modeled yet. Their implementations and their effects are described in the next section. 


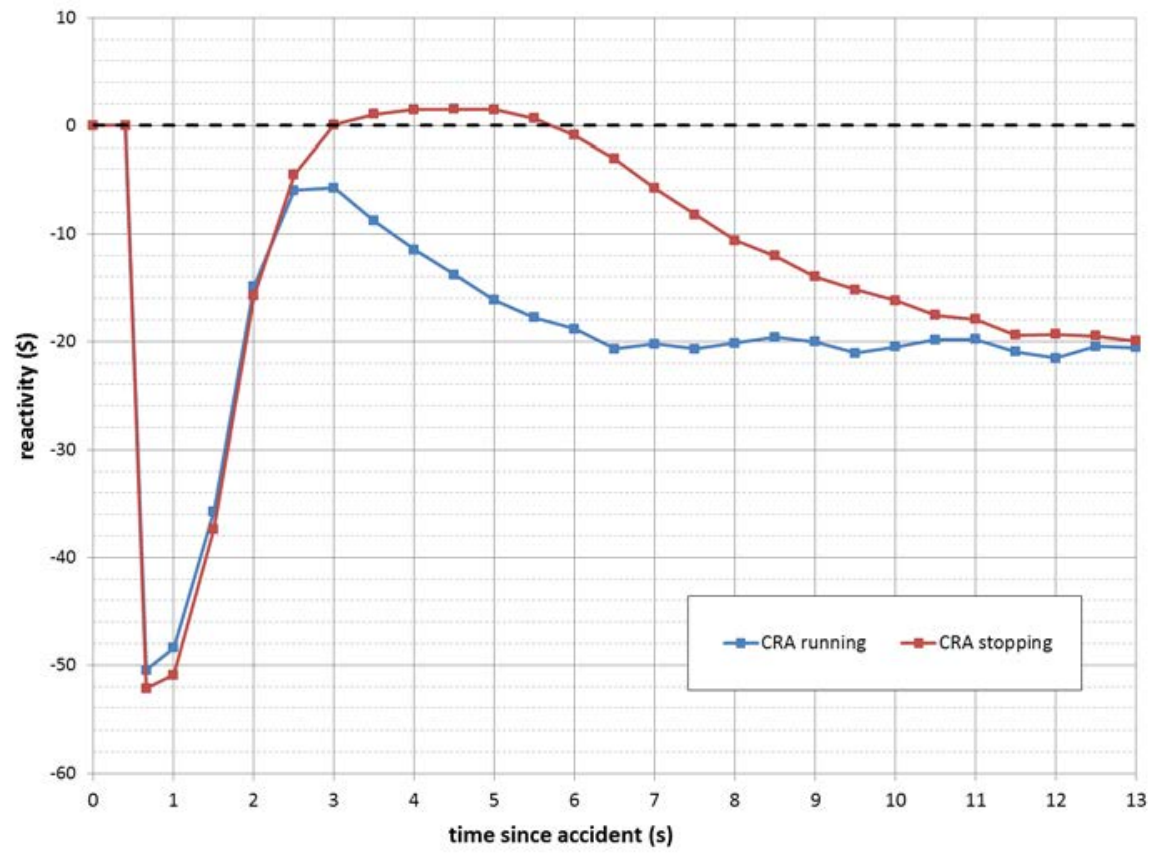

Figure 4.2-4 - Evolution of the reactivity calculated with MCNP using RELAP5 calculated time-dependent light water concentration

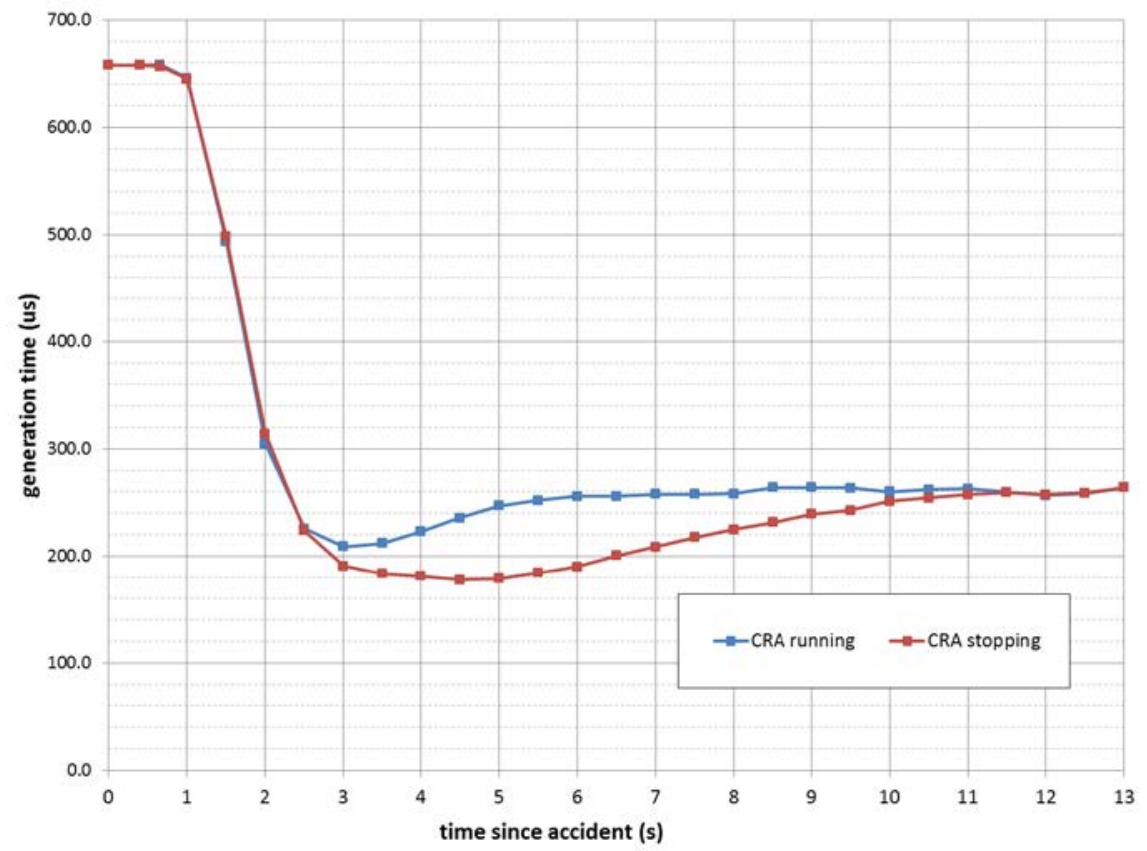

Figure 4.2-5 - Evolution of the neutron prompt generation time calculated with MCNP using RELAP5 calculated time-dependent light water concentration 


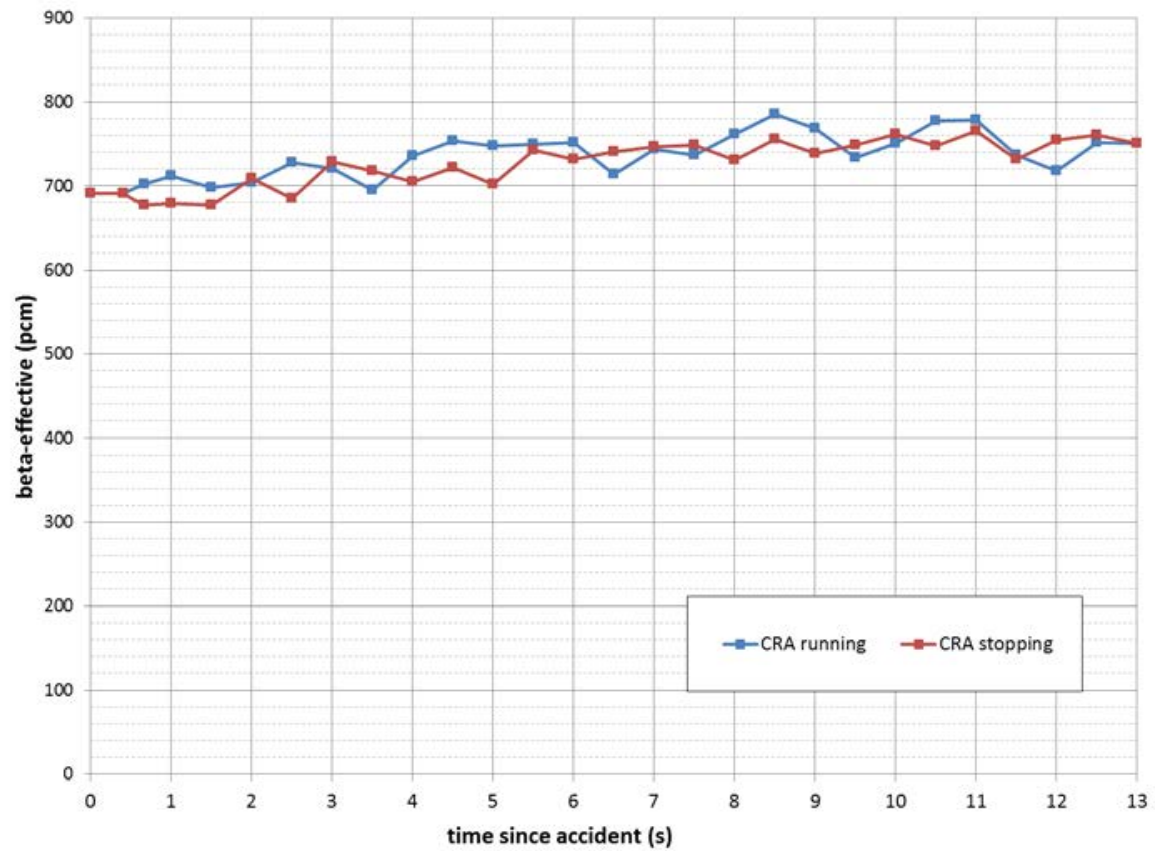

Figure 4.2-6 - Evolution of the beta-effective calculated with MCNP using RELAP5 calculated time-dependent light water concentration

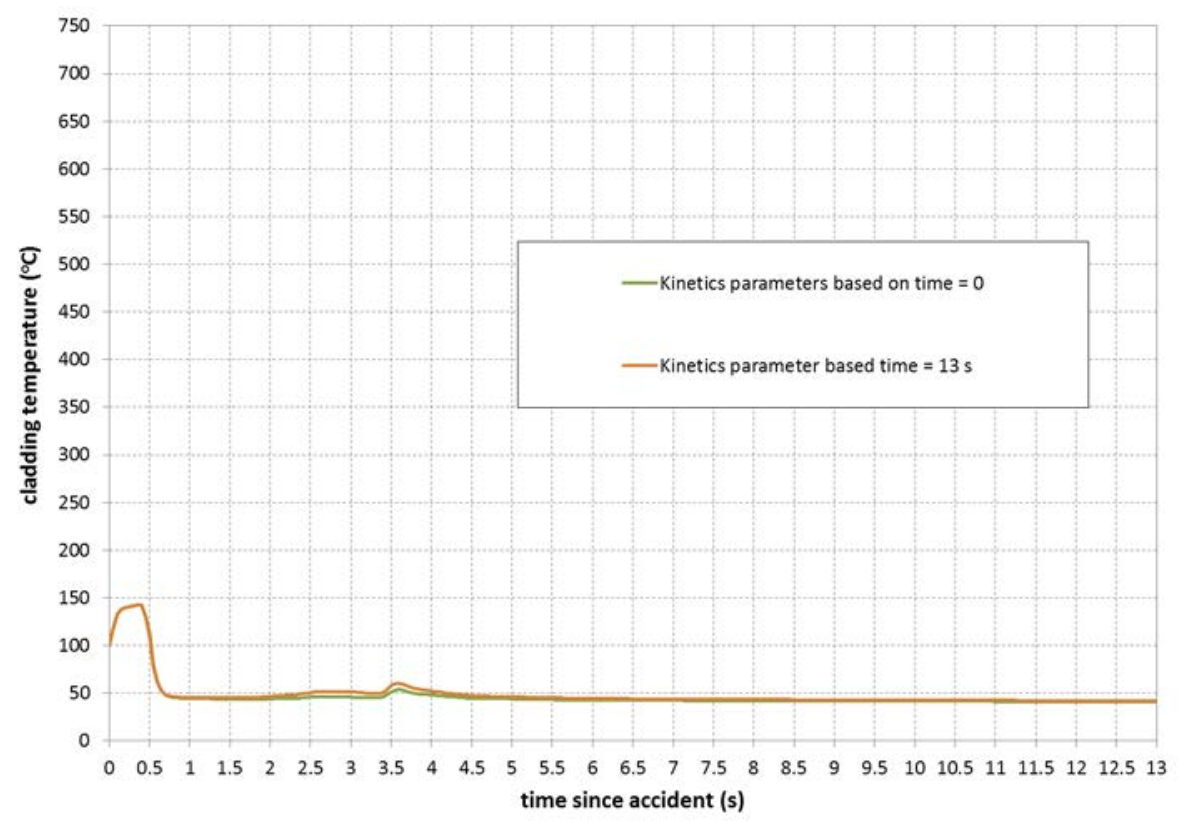

Figure 4.2-7 - Evolution of the peak cladding temperature for the case CRA pumps running 


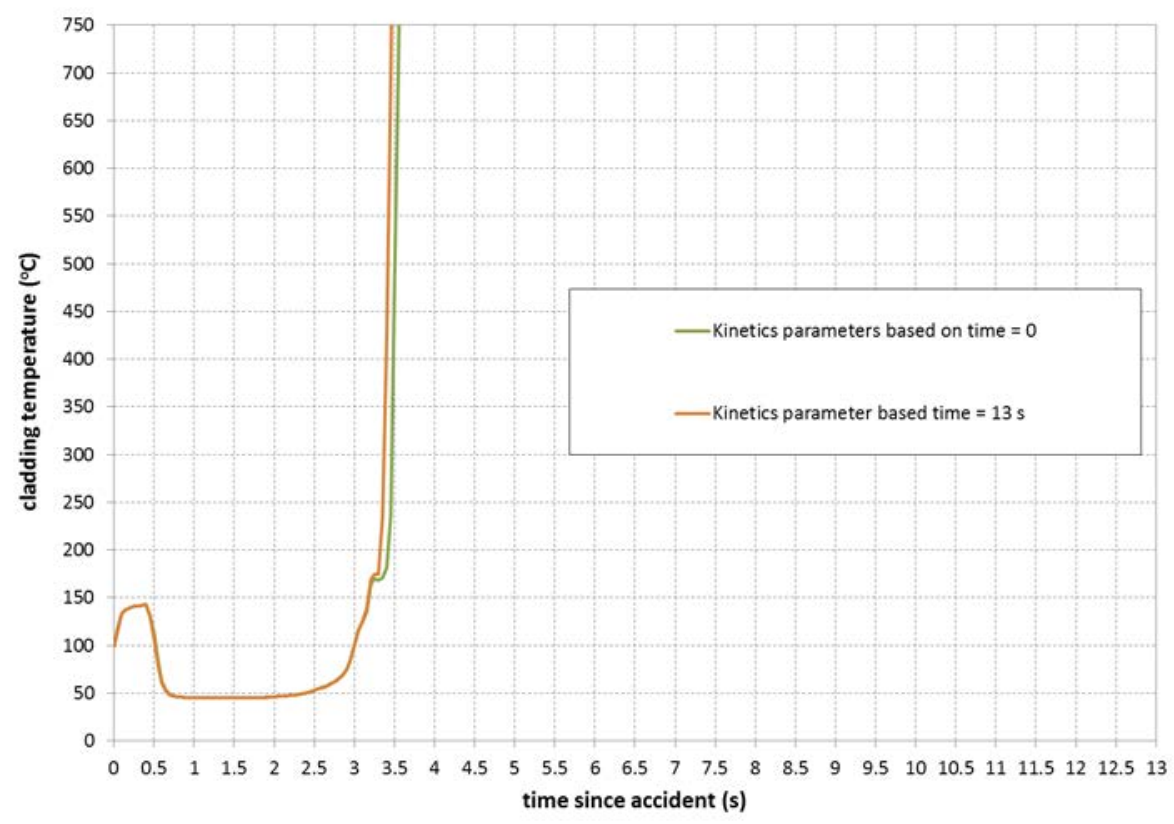

Figure 4.2-8 - Evolution of the peak cladding temperature for the case CRA pumps stopping

\subsection{RELAP5/MCNP Loose Coupling \& Void Feedback Coefficients}

In this final step, the void feedback coefficient, presented in figure Figure 4.3-1, is implemented in the case of CRA pumps stopping, which is the only one to predict boiling. The void feedback coefficient presented in Figure 4.3-1 has been calculated by changing the density of the coolant between the plates from its liquid to its vapor phase value. From the beginning to the end of the sequence, it can be seen that the void coefficient is significantly negative and tends to decrease when the light water concentration present in the fuel element increases. Fuel, clad and coolant temperature coefficient have been calculated but their magnitudes are so small compared that to the void feedback coefficient that is has been judged unnecessary to model them.

The case with CRA pumps stopping has been re-ran using a constant value for the void coefficient equal, conservatively, to $-40 \$$ (the highest value obtained in the sequence). The new peak clad temperature evolution is shown in Figure 4.3-2 and compared to the case where the void coefficient is not modeled. The new temperature profile is very similar to the previous one until $t=3.25 \mathrm{~s}$, as one can expect since no boiling occurs during this phase. However, for $t>3.25 \mathrm{~s}$, when significant boiling start to occur, the void coefficient is so negative that the reactivity becomes very quickly negative, leading to a cool down and vapor disappearance. Using the constant, conservative, void feedback coefficient value, the same phenomena repeats itself several time during the phase where the reactivity is positive. During that phase (until $t=5.5 \mathrm{~s}$ ), the peak clad temperature never exceeds $175^{\circ} \mathrm{C}$ well below the clad failure temperature. Once the light water enters the central cavity, the reactivity becomes negative, no boiling occurs anymore and the peak clad temperature gradually drops to stabilize around $50^{\circ} \mathrm{C}$ like for the case with CRA pumps running.

This finding seems to show that even if the CRA pumps were to stop, the reactor would remain safe. 


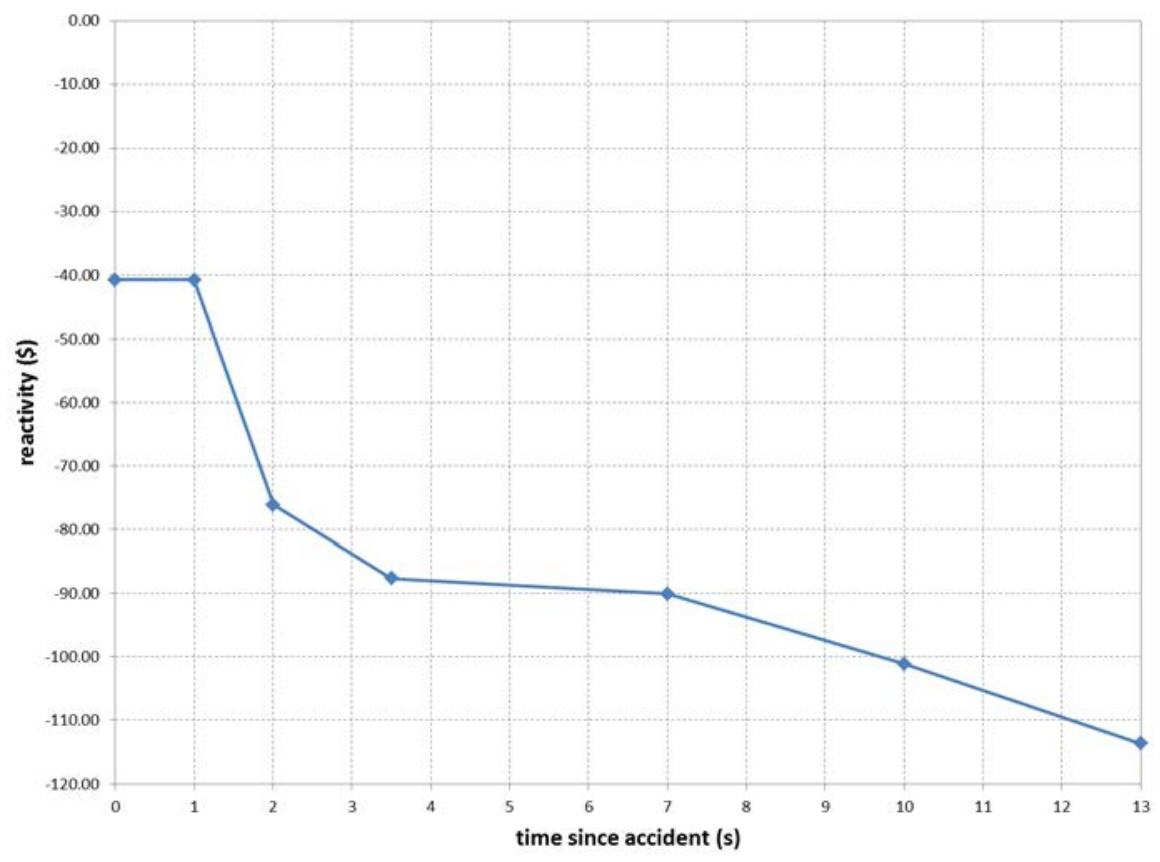

Figure 4.3-1 - void feedback coefficient for the case CRA loop stopping

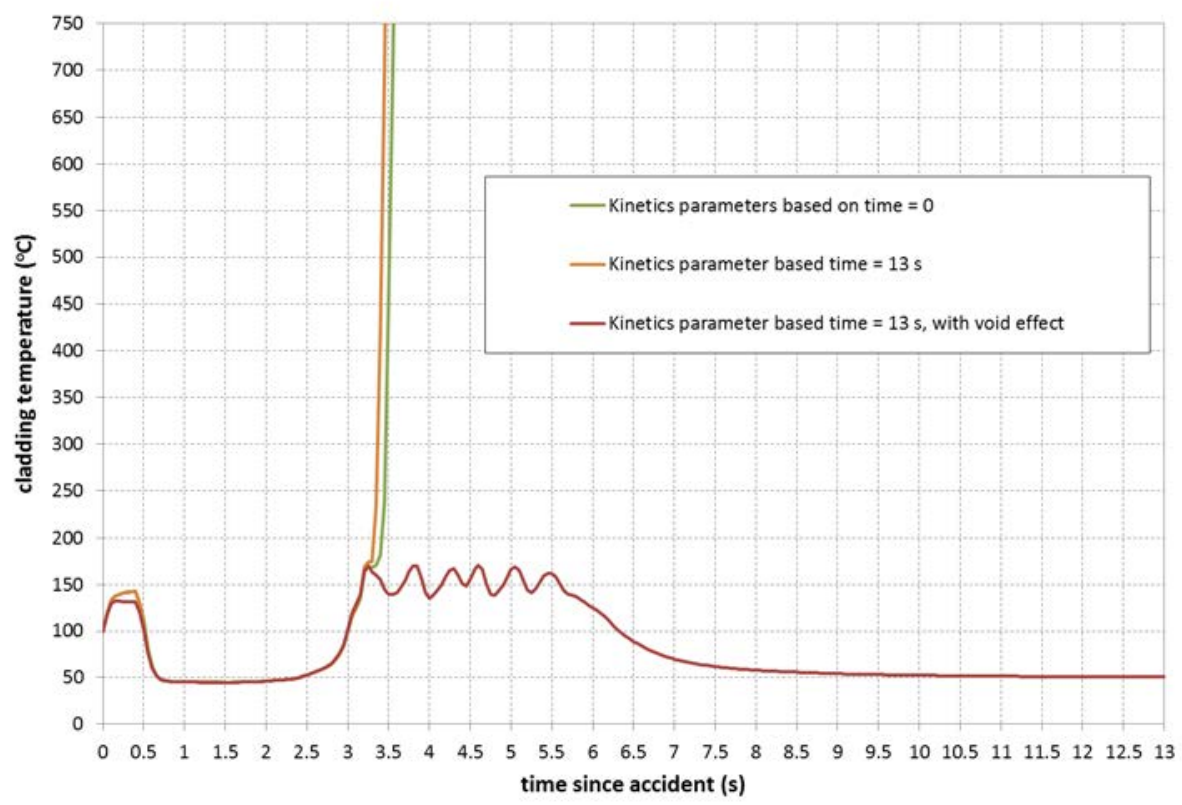

Figure 4.3-2 - Evolution of the peak cladding temperature for the case CRA pumps stopping with and without void feedback coefficient 


\section{Conclusions}

The consequences of a large light water ingress in the heavy water RHF reactor have been analysed. In the currently approved RHF SAR, it is stated that the excess reactivity supplied by the light water would be more than compensated by the insertion of the safety rods. Therefore, the core would remain safe.

Neutronic calculations performed in this work show that RHF SAR conclusions are indeed accurate but only after a certain time, when the light water has time to fill the central cavity. Calculations show that there will be a period of time where the k-effective will be well above one. This is caused by the significant difference of coolant velocity between the element and the central cavity. This velocity difference will lead to a situation where the light water is present between the plates but is not present in sufficient quantity in the central cavity which lead to a very unfavorable state where the k-effective will exceed one. Insertion of the four less efficient safety rods would not be sufficient to compensate this excess reactivity. A neutronic tool is therefore not sufficient, on its own, to describe the relevant phenomena occurring in this accident scenario.

A loose coupling between neutronic and safety analysis tools has been used to implement a more realistic evolution of the core reactivity. This evolution of the reactivity depends of the time and space dependent concentration of light water in the core as well as phase change and void feedback coefficient. Analysis shows that the reactor would remain safe (cladding temperature far below melting temperature) at any time even assuming conservatively that the CRA pumps trip immediately after the break is detected. The dominant factor here is the void feedback coefficient which is found to be strongly negative.

This preliminary analysis therefore concludes that a large light water ingress would be unconsequential for the fuel integrity and reactor safety. 


\section{References}

[Bergeron, 2010] A. Bergeron, A. Tentner, J.G. Stevens: "Feasibility Analyses for HEU to LEU Fuel Conversion of the Laue-Langevin Institute (ILL) High Flux Reactor (RHF)", Argonne National Laboratory, ANL/RERTR/TM-10-21, 2010.

[Dionne, 2014]

[ILL, 2017]

B. Dionne et al., "Summary of RELAP5 Assessments Performed in Relation to Conversion Analysis of Research Reactors", Argonne National Laboratory, ANL/GTRI/TM-14-3, 2014.

Institut Laue-Langevin website,

https://www.ill.eu/

Consulted August $1^{\text {st }}, 2017$

[ISL, 2003]

RELAP5/MOD3.3 Code Manual, Nuclear Safety Analysis Division, July 2003, Information Systems Laboratories, Inc., Rockville, Maryland, and Idaho Falls, Idaho.

[LANL, 2008a]

X-5 Monte Carlo Team: "MCNP - A General Monte Carlo N-Particle Transport Code, Version 5 Volume II: User's Guide", Los Alamos National Laboratory, LA-CP03-0245, 2/1/2008 revision.

[LANL, 2008b] X-5 Monte Carlo Team: "MCNP - A General Monte Carlo N-Particle Transport Code, Version 5 Volume I: Overview and Theory", Los Alamos National Laboratory, LA-CP-03-1987, 2/1/2008 revision.

[Licht, 2015]

J. R. Licht et al., "Verification of Historical System Transient Simulations for the RHF Research reactor", Argonne National Laboratory, ANL/RTR/TM-15/5, 2015.

[Vised, 2014]

MCNP Visual Editor website: http://www.mcnpvised.com/ 
(This page left intentionally blank) 


\section{Argonne $\mathbf{A}$}

Nuclear Engineering Division

Argonne National Laboratory

9700 South Cass Avenue, Bldg. 208

Argonne, IL 60439

www.anl.gov

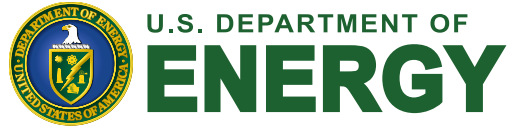

Argonne National Laboratory is a U.S. Department of Energy laboratory managed by UChicago Argonne, LLC 